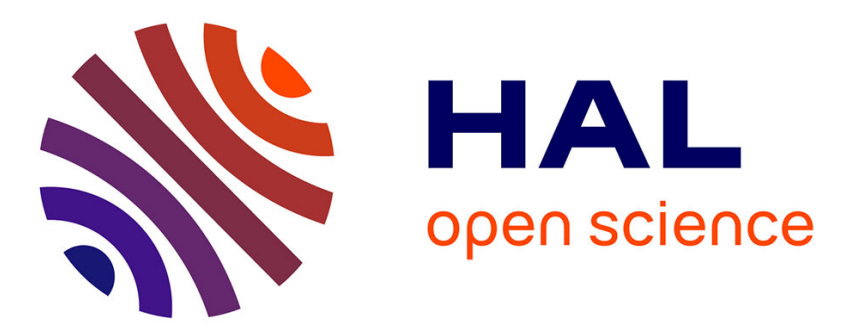

\title{
Coordination of mitochondrial biogenesis by thyroid hormone
}

\author{
Joachim M. Weitzel, K. Alexander Iwen
}

\section{To cite this version:}

Joachim M. Weitzel, K. Alexander Iwen. Coordination of mitochondrial biogenesis by thyroid hormone. Molecular and Cellular Endocrinology, 2011, 342 (1-2), pp.1. 10.1016/j.mce.2011.05.009 . hal-00721652

\section{HAL Id: hal-00721652 \\ https://hal.science/hal-00721652}

Submitted on 29 Jul 2012

HAL is a multi-disciplinary open access archive for the deposit and dissemination of scientific research documents, whether they are published or not. The documents may come from teaching and research institutions in France or abroad, or from public or private research centers.
L'archive ouverte pluridisciplinaire HAL, est destinée au dépôt et à la diffusion de documents scientifiques de niveau recherche, publiés ou non, émanant des établissements d'enseignement et de recherche français ou étrangers, des laboratoires publics ou privés. 


\section{Accepted Manuscript}

Review

Coordination of mitochondrial biogenesis by thyroid hormone

Joachim M. Weitzel, K. Alexander Iwen

PII:

S0303-7207(11)00250-4

DOI:

10.1016/j.mce.2011.05.009

Reference:

MCE 7841

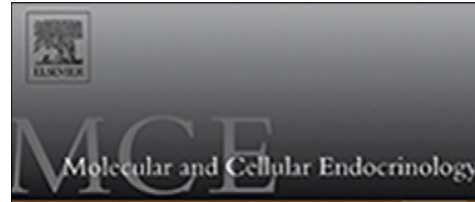

To appear in: $\quad$ Molecular and Cellular Endocrinology Molecular and Cellular Endocrinology

Received Date: $\quad 4$ April 2011

Revised Date: $\quad 28$ April 2011

Accepted Date: $\quad 15$ May 2011

Please cite this article as: Weitzel, J.M., Alexander Iwen, K., Coordination of mitochondrial biogenesis by thyroid hormone, Molecular and Cellular Endocrinology Molecular and Cellular Endocrinology(2011), doi: 10.1016/j.mce. 2011.05.009

This is a PDF file of an unedited manuscript that has been accepted for publication. As a service to our customers we are providing this early version of the manuscript. The manuscript will undergo copyediting, typesetting, and review of the resulting proof before it is published in its final form. Please note that during the production process errors may be discovered which could affect the content, and all legal disclaimers that apply to the journal pertain. 
Coordination of mitochondrial biogenesis by thyroid hormone.

\title{
Joachim M. Weitzel ${ }^{1}$ and K. Alexander Iwen $^{2}$
}

${ }^{1}$ Forschungsbereich Fortpflanzungsbiologie, Leibniz-Institut für Nutztierbiologie, FBN

Dummerstorf, Germany; ${ }^{2}$ Medizinische Klinik I, Universitätsklinikum Schleswig-Holstein, Lübeck, Germany.

\author{
Correspondence address: \\ Department of Reproductive Biology, FBN Dummerstorf, \\ Wilhelm-Stahl-Allee 2, 18196 Dummerstorf, Germany. \\ Tel.: +49-38208-68788 \\ Fax: $+49-38208-68752$ \\ E-mail: weitzel@fbn-dummerstorf.de
}

Running title: $\mathrm{TH}$ and mitochondrial biogenesis. 


\begin{abstract}
Thyroid hormone (TH) has profound influence on metabolism that is closely linked to its effect on mitochondrial biogenesis and function. After a single injection of TH into mammals, physiological alterations (e.g. changes in oxygen consumption rates) are detectable after a lag period of $\sim 48$ hours. This characteristic lag period is somewhat surprising since non-genomic responses are already detectable within minutes, and first genomic responses within some hours after administration of TH. This review provides a model to explain the characteristic lag period: TH regulates a first series of TH target genes via classical activation of gene expression by binding to thyroid hormone response elements. Some directly regulated target genes serve as intermediate factors and subsequently regulate a second series of indirect $\mathrm{TH}$ target genes. Intermediate factors are transcription factors (such as NRF-1, NRF-2 and PPAR $\gamma$ ) and transcriptional coactivators (such as PGC-1 $\alpha$ and PGC-1 $\beta$ ). In concert with several post-transcriptional modifications, these intermediate factors orchestrate the physiological response to thyroid hormone in vivo.
\end{abstract}

\title{
Key words
}

Thyroid hormone, mitochondria, nuclear-mitochondrial crosstalk, coactivator, gene regulation, signal pathway.

\section{Abbreviations}

$\mathrm{TH}$, thyroid hormone; TR, thyroid hormone receptor; TRE, TH response element; NRF, nuclear respiratory factor; PPAR, peroxisome proliferator-activated receptor; PGC, PPAR coactivator; T4, 3,5,3',5'-tetraiodo-L-thyronine; T3, 3,3',5-triiodo-L-thyronine. 


\section{Introduction}

Thyroid hormone (TH) is essential for normal development and health. Thyroid dysfunction causes a wide spectrum of clinical symptoms, depending on onset and severity of $\mathrm{TH}$ deficiency or TH excess. Cretinism is a well-known condition of congenital TH deficiency emphasising the requirement of TH for normal development in humans; although this disorder is rarely seen in developed countries. Thyroid dysfunction in normally developed children and adults is more common. The prevalence of hypothyroidism varies between 3 and $10 \%$; it may reach up to $21 \%$ in elderly women (Roberts and Ladenson, 2004). Hyperthyroidism is not as common, less than $1 \%$ of individuals in a general population are affected (Cooper, 2003). Overt hypothyroidism is associated with weight gain, cold intolerance, dry skin, and impaired mental processing. Clinical features of hyperthyroidism include weight loss, heat sensitivity, and warm moist skin, indicating profound metabolic changes. In hyperthyroid individuals, these changes include increases in oxygen consumption, metabolic rate, and temperature, which occur within 24 to 48 hours after the onset of hyperthyroidism or administration of TH to humans or animals (TATA et al., 1963). Figure 1 displays rises of metabolic rates in hypothyroid rats after the injection of TH. It shows a characteristic 'lag period' of approximately 48 hours, after which TH-mediated metabolic changes can be detected.

\#\#\# Figure 1 \#\#\#

The ability of TH to regulate energy utilization is closely linked to its effect on mitochondrial function. Mitochondria provide $90 \%$ of intracellular energy demand in the form of ATP, making mitochondria a target of TH (Harper and Seifert, 2008). The complex mechanisms of TH action on mitochondria are still under investigation and it is important to keep an important aspect in mind: Mitochondrial DNA contains 37 genes, but approximately 1200 to 1500 gene-products can be found in a mitochondrion (DiMauro and Schon, 2003; Schmidt et al., 2010). Although the majority of these products are encoded in the nucleus, wellorchestrated intracellular mechanisms are essential to ensure mitochondrial function. This article reviews the intracellular molecular basis of TH-mediated effects on mitochondrial function and biogenesis. Different signal molecules, hormone receptors, and regulating proteins as well as mechanisms underlying the characteristic lag period of TH-action will be discussed. 


\section{Signal molecules and local bioavailability}

It has been assumed that T4 (L-thyroxine) is the major secretion product of the thyroid gland, which is subsequently converted into the biologically more potent T3 (triiodo-L-thyronine). However, novel data create a more complex picture. A variety of alternative products of T4 play important roles in modulating TH effects: deiodinases convert T4 into rT3, which is biologically rather inactive, or T2 (diiodo-L-thyronine) which might directly target the mitochondrion. T4 and derivates thereof may also be sulphated or oxidative deaminated, causing further diverse metabolic changes. The discovery of thyronamines adds additional players on the scene. Chemically, thyronamines are decarboxylated TH derivatives, but their function largely opposes TH effects. It should also be kept in mind that the local intracellular bioavailability of different $\mathrm{TH}$ molecules is regulated by several TH transporters. These transporters exhibit different transport specificities for different TH molecules and show a heterogeneous tissue distribution pattern. These important aspects of TH metabolism and specificity have been recently reviewed in excellent and comprehensive review articles elsewhere (Moreno et al., 2008; Friesema et al., 2010; Piehl et al., 2011). In this article, we will use the rather global term 'thyroid hormone' (or TH) to describe intracellular changes after administration of T4 or T3 into hypothyroid animals and focus on the intracellular actions of TH.

\section{Thyroid hormone receptors}

- Nuclear receptors

Thyroid hormone receptors (TRs) belong to a large family of ligand-dependent transcription factors. This family includes nuclear hormone receptors for sex steroids, vitamins, xenobiotics, and orphan receptors with no identified ligand. TRs are encoded on two distinct genes $(\alpha$ - and $\beta$-gene). Alternative splicing and alternative translation give rise to at least a dozen functionally different TR proteins (Cheng et al., 2010). The archetypical TR binds to thyroid hormone response elements (TREs) on the DNA, which classically consist of two half-sites for which the canonical sequence is 5'-AGGTCA-3'. Typically, TREs have been detected within $\sim 1000 \mathrm{bp}$ upstream of the transcriptional start site in TH-regulated gene promoters. However, sequences, orientation of TREs and spacer lengths between the half sites differ greatly between different TRE and TRE-like sequences. Furthermore, novel analyses of artificial TRE sequences challenge this classical TRE paradigm. In vitro assays revealed that 
consensus TREs confer high binding affinity but poor specificity for TR (Phan et al., 2010). Other studies revealed TR-binding to DNA sequences, which did not contain TRE consensus sequences. Recent ChIP-on-Chip assays failed to identify TRE or TRE-like sequences within TR-immunoprecipitated DNA (Dong et al., 2009). Chromatin immunoprecipitation assays did not distinguish between proteins directly bound to DNA from proteins indirectly bound as part of the chromatin complex. Underlying mechanisms remain to be elucidated.

\section{- Mitochondrial receptors}

An alternative translation product of the TR $\alpha$ gene (p43) has been primarily localised inside mitochondria. This protein is devoid of $2 / 3$ of the $\mathrm{N}$-terminal activation domain AF- 1 but contains intact DNA binding, ligand binding and ligand-depending activation (AF-2) domains. p43 binds to several TRE-like sequences on the mitochondrial genome and stimulates transcription in the presence of TH in a ligand-dependent manner (Casas et al., 1999). Overexpression of $\mathrm{p} 43$ in cell culture and in vivo increases mitochondrial transcription and protein synthesis (Casas et al., 1999; Casas et al., 2009). Muscle-specific overexpression leads to a switch of muscle fibre composition, increased mitochondrial respiration and increased body temperature in transgenic mice. Thus the truncated primarily mitochondrial localised p43 version resembles properties of the full-length nuclear located TR. Long term overexpression leads to increased skeletal muscle atrophy during aging probably due to increased oxidative stress (Casas et al., 2009). Several aspects of mitochondrial TRs need to be elucidated, including the exact import mechanisms of p43 and its ligand into the mitochondrion. Yet, there is an increasing amount of data indicating a localisation of TR, other nuclear transcription factors as well as transcriptional cofactors in mitochondria (LeighBrown et al., 2010; Psarra and Sekeris, 2009; Aquilano et al., 2010). Thus, the mitochondrial as well as the nuclear genome appear to be regulated in a very similar manner in response to TH.

\section{Coactivators and Corepressors}

Upon TH administration, transcription rates of targeted genes are either increased or decreased. Underlying mechanisms of increased transcription rates have been well studied and involve coactivators: TRs are ligand-dependent transcription factors which modulate gene transcription depending on the presence or absence of T3 (Cheng et al., 2010). The liganded transcription factor recruits a large coactivator complex. This complex possesses or recruits 
enzymatic activities which alters chromatin of target genes and generates an open structure for transcription. In the absence of T3, the unliganded TR undergoes conformational changes and recruits a corepressor complex. Again, this corepressor complex integrates several enzymatic activities which modify chromatin towards a closed structure, resulting in a transcriptional silent state. On the other hand, mechanisms of negatively TH-regulated genes in the presence of T3 are less clear (Weitzel, 2008; Santos et al., 2011) but the balanced recruitment of corepressors might play an important role.

Limited data is available about the regulation of cofactors. Coactivators and corepressors bind to multiple transcription factors and are rather ubiquitously expressed throughout the organism. Only a few cofactors are known to be regulated by endocrine or metabolic stimuli, e.g. the PGC-1 family of coactivators or their inverse agonist RIP140 (Hock and Kralli, 2009; Park et al., 2009).

\section{TH regulation of gene expression}

Proteomics and transcriptomics studies indicated that approximately $8 \%$ of total liver proteins are regulated by TH in vivo (Silvestri et al., 2006; Feng et al., 2000; Weitzel et al., 2001; Flores-Morales et al., 2002; Weitzel et al., 2003; Stahlberg et al., 2005; Bungay et al., 2008). Considering the profound influence of TH on metabolism and the important role of the liver in energy homeostasis, these results are not surprising. Yet, similar results have been observed in other tissues in vivo (such as skeletal muscle) and in cell culture experiments (Clement et al., 2002; Helbing et al., 2003; Miller et al., 2001; Shih et al., 2004), thereby emphasising the importance of TH in systemic physiology. Differentially regulated genes are involved in a wide variety of cellular functions including translation, protein turnover, apoptosis, and metabolism. Mitochondrial proteins, encoded in the nucleus as well as in mitochondria, are among TH-target genes. All mentioned studies identified comparable number of regulated genes, but these are not always identical. However, it should be pointed out that early and late TH-mediated gene expression patterns (see below) have been conserved independent of the particular experimental setting.

Compared to the large number of differentially TH-regulated genes in vivo, only few genes have been proven to be directly regulated via TREs, and a growing number of target genes lack TREs (Weitzel et al., 2003). Classically it has been assumed that functional TREs are located within $\sim 1000$ bp upstream of the transcriptional start site, but TREs have also been identified far upstream of this suggested region (Chen et al., 2008; Wulf et al., 2008). Our 
view on TRE or TRE-like sequences might be biased by our expectation to detect these sequences relatively close to the transcriptional start site. As a consequence other TREs might have been overlooked. Further experimental studies are needs to detect functional TREs in 'unexpected' regions and to elucidate TRE-independent mechanisms of TH-mediated gene expression.

\section{Time courses of TH-regulated gene expression in vivo}

After TH-injection into hypothyroid rats, two different expression patterns of genes have been observed. The first expression pattern ('early expression') is characterised by changes of mRNA levels within $6 \mathrm{~h}$ after the administration of $\mathrm{TH}$, and the second pattern ('late expression') by unaffected mRNA concentrations within the first $24 \mathrm{~h}$, but profound changes $48 \mathrm{~h}$ after TH-treatment (Weitzel et al., 2001; Weitzel et al., 2003). These expression patterns have not only been found in liver but also in whole organisms (e.g. Xenopus laevis), different rodent tissues, and different cell models (Helbing et al., 2003; Quignodon et al., 2007; Chattopadhyay et al., 2007; Miller et al., 2001; Shih et al., 2004).

A very interesting example of TH action in vivo is metamorphosis in Xenopus laevis. It is characterised by a non-functional thyroid gland in embryos, which gains function during larval development. Serum TH levels are detectable shortly after the formation of the functional gland and consequently trigger metamorphosis. Microarrays and subtractive hybridisation approaches confirmed early and late gene induction (Denver et al., 1997; Helbing et al., 2003). In pituitary GC cells and HepG2 cells (stably expressing functionally active TRs), both patterns have also been observed (Miller et al., 2001; Shih et al., 2004). These in vitro results indicate intracellular mechanisms, because other important in vivo aspects of TH, such as changes in local bioavailability or indirect effects like TH-mediated alterations of the sympathetic nervous system, are excluded.

Thus, expression profiles in different organs of rodents, in Xenopus laevis and different cell lines are very similar, indicating an evolutionary conserved principle of TH action.

\section{Post-translational modification}

An important cross-talk between genomic and non-genomic pathways of TH action may be mediated by post-translational modifications of TR. 
The MAP kinase pathway is classically regulated by activation of cell surface G proteincoupled receptors, yet $\mathrm{T} 3$ and even more potently $\mathrm{T} 4$, are able to activate this pathway within 20 minutes without entering the cell (Bergh et al., 2005); summarised in (Cheng et al., 2010). Apart from this non-genomic action TH additionally induces components of the MAP kinase pathway at the transcript level (Weitzel et al., 2001; Weitzel et al., 2003). The other way round MAP kinases modulate the transcriptional activity of TR via phosphorylation. Davis and colleagues described phosphorylation of TR $\beta$ at Ser-142 within the DNA binding domain (DBD) (Lin et al., 2003). Interestingly, this particular serine residue is not conserved in TR $\alpha$. Thus, the functional consequences of phosphorylation of different TR isoforms remains controversial (Chen et al., 2003; Mochizuki et al., 2007). Other modifications of TR also interfere with transcriptional activity. T3 triggers an increased ubiquitination of TR $\beta$ within the ligand-binding domain, causing proteasomal degradation (Dace et al., 2000). Beside phosphorylation and ubiquitination, acetylation at three defined sites within the hinge domain of TR $\alpha$ has also been described and might interfere with DNA binding and transactivation (Sanchez-Pacheco et al., 2009).

Interestingly, differences in post-translational modification between alpha and beta isoform of TR are apparent: phosphorylation has only been characterised for $\mathrm{TR} \alpha$, whereas acetylation and ubiquitination have solely been described for TR $\beta$. Post-translational modifications are not only important for TR, transcriptional coactivators and corepressors, which are essential for TR function, are modified in a similar manner (Hock and Kralli, 2009). Thus, the MAP kinase pathway and probably other signal transduction pathways appear to be integrated in TH-signalling in both, genomic and in non-genomic ways (Figure 2).

\#\#\# Figure 2 \#\#\#

\section{Different pathways of TH-regulated gene expression}

The characteristic lag period of $\sim 48$ hours after which physiological alterations are detectable upon TH administration is somewhat surprising. Many genes regulated within 6 hours after administration of TH contain well characterised TREs. Examples are mGPDH/GPD2 (Weitzel et al., 2000), furin (Chen et al., 2008), PGC-1 $\alpha$ (Wulf et al., 2008) or BTEB1/K1f9 (Denver and Williamson, 2009). Hence, these target genes might be directly regulated via binding of TR to the regulatory elements within their gene promoter regions. In contrast, in numerous genes, which are induced late $(>24 \mathrm{~h})$ after the administration of TH in hypothyroid rats, no TRE has been identified so far (Weitzel et al., 2003). This raises the question whether these 
genes are regulated via an indirect mechanism or probably by an intermediate factor (Figure 3 ), providing a molecular explanation for the late expression pattern.

\#\#\# Figure 3 \#\#\#

\section{Transcription factors as intermediate factors of $\mathbf{T H}$ action}

An intermediate factor of $\mathrm{TH}$ action might be a transcription factor. If so, this transcription factor needs to fulfil several prerequisites: (i) this factor need to be induced fast (early expression) and (ii) binding sites for this factor need to be detectable in promoter regions of late induced genes.

\section{Ubiquitous transcription factors and nuclear receptors}

Binding sites for transcription factors CREB, Sp1 and Yin Yang 1 (YY1) are frequently found in gene promoters of mitochondrial proteins showing a late expression pattern (Franko et al., 2008; Scarpulla, 2008). This makes them prime candidates for intermediate factors. However, none of this transcription factors is significantly regulated by T3 within 6 hours (Weitzel et al., 2003). Similar results have been observed for other candidate transcription factors such as HNF-4 $\alpha$, Tfam and HCF. It should also be noted that almost 20 years ago conserved binding sites within mitochondrial proteins have been suggested to play a role in $\mathrm{TH}$-mediated gene expression (e.g. OXBOX/REBOX and Mt motifs). However, the binding proteins to these sites are still unknown and no further development has been achieved in the last years (Rebelo et al., 2009).

Upon TH-administration, the nuclear receptor PPAR $\gamma$ is down-regulated 2-fold on transcript and protein levels within hours (Weitzel et al., 2003). Since PPAR and TR proteins bind to similar DNA response elements a depletion of PPAR $\gamma$ might favour a binding of TR to these sites. Furthermore, PPAR and TR have the same preferred dimerisation partner (RXR) thus reduced PPAR might favour TR/RXR complexes.

\section{Nuclear respiratory factors}

Binding sites for the nuclear respiratory factors 1 and 2 (NRF-1 and NRF-2) have been observed in numerous nuclear-encoded mitochondrial proteins and many of these sites have been proven to be critical for promoter activities (Scarpulla, 2008). The important role of NRF-1 in mitochondrial integrity and function has been shown by targeted gene disruption in 
mouse. Knock-out of NRF-1 is embryonic lethal associated with dramatically reduced number and function of mitochondria (Huo and Scarpulla, 2001). NRF-1 is rapidly and robustly regulated by TH (Venditti et al., 2009; Weitzel et al., 2001) and thus NRF-1 is clearly one of the factors which translate TH effects.

Very similar observations have been made with NRF-2 (also known as GA-binding protein, GABP). Again NRF-2 binding sites have been characterised in the promoter region of many nuclear-encoded mitochondrial genes, several (but not all) contain NRF-1 binding sites as well (Scarpulla, 2008). NRF-2 is a protein which is alternatively composed from a set of five different subunits $(\alpha, \beta 1, \beta 2, \gamma 1$ and $\gamma 2)$. DNA-bound NRF-2 is a heterotetramer which contains either two alpha and two beta or two alpha and two gamma subunits. The beta and gamma subunits appear to be generated from a common gene by alternative splicing containing trans-activation domains, whereas the unique alpha subunit contains the DNA binding domain (Gugneja et al., 1995). There are conflicting data in the literature concerning the regulation of NRF-2 by thyroid hormone which might be ascribed to the regulation of the different subunits and to the investigation of different time points after administration of $\mathrm{TH}$. Whereas the beta subunit is only slightly regulated within 6 hours (Weitzel et al., 2001), the alpha subunit has been described to be positively and negatively regulated after 3 and 10 days, respectively (Rodriguez-Pena et al., 2002; Venditti et al., 2009). Knock-out of NRF-2 $\alpha$ in mice leads to early embryonic lethality showing a very similar phenotype as NRF-1 knockouts (Ristevski et al., 2004). An alteration of the mitochondrial status has not been tested in those mice; however, mitochondrial marker genes are down-regulated in NRF-2 $\alpha$ knockdown cells (Ongwijitwat et al., 2006).

Taken together, these data show that NRF-1 (and possibly also NRF-2) translate TH effects in an indirect manner as these proteins meet three important requirements: (i) the protein is endogenously regulated by TH, (ii) this regulation occurs fast (within 6 hours, probably via a TRE), and (iii) functional binding sites have been characterised in late TH-induced genes.

\section{Coactivators as intermediate factors of TH action}

Transcriptional activity of target genes does not solely depend on the action of transcription factors but also on the activity of coactivators and corepressors. Thus an attractive approach to identify an intermediate factor is to investigate this group of proteins. Noteworthy, these factors do not bind directly to DNA and therefore a common DNA binding motif is not 
necessarily detectable. An attractive candidate for an intermediate factor is the PGC-1 family of coactivators.

\section{PGC-1 family of coactivators}

The first identified member of the PGC-1 family of coactivators is peroxisome proliferatoractivated receptor gamma coactivator 1 alpha (PGC-1 $\alpha$ ). PGC-1 $\alpha$ has profound influence on adaptive thermogenesis in brown adipose tissue, hepatic gluconeogenesis and mitochondrial biogenesis thereby resembling effects of TH. Furthermore, PGC- $1 \alpha$ coactivates a variety of nuclear receptors and nuclear respiratory factors, including the thyroid hormone receptor (Puigserver et al., 1998; Sadana et al., 2007; Attia et al., 2010).

PGC-1 $\alpha$ is rapidly and robustly induced by TH both on transcript (13-fold) and protein levels (3-fold) (Irrcher et al., 2003; Weitzel et al., 2003; Venditti et al., 2009), this regulation is mediated by a TRE in the gene promoter (Wulf et al., 2008). Interestingly, PGC-1 $\alpha$ has also been described to be located into the mitochondria; however, more experimental evidence is needed to clarify this issue (Aquilano et al., 2010). Surprisingly, PGC-1 $\alpha$ knock-out mice have relative subtle alterations in mitochondrial biogenesis and architecture (Ventura-Clapier et al., 2008; Hock and Kralli, 2009) and knock-down in cell culture revealed no major defects in TH-mediated gene expression patterns (Wulf et al., 2007). Thus, compensatory mechanisms might be in place, possibly by other coactivators of the PGC-1 family. A second family member is PGC- $1 \beta$, considering sequence and functional activity it is very closely related to PGC-1 $\alpha$. PGC-1 $\beta$ activates mitochondrial biogenesis by binding to different transcription factors (including TR). However, there is an important difference between these two coactivators. PGC-1 $\beta$ has been shown to be rapidly and robustly induced by TH (6-fold) (Weitzel et al., 2003), suggesting a direct regulation via a TRE.

In contrast to PGC-1 $\alpha$ and PGC-1 $\beta$ the third family member (PRC; PGC-1-related coactivator) is not significant regulated by TH (Weitzel et al., 2003).

Taken together, PGC-1 $\alpha$ and PGC-1 $\beta$ (but not PRC) meet the important requirements to serve as intermediate factor: (i) PGC- $1 \alpha / \mathrm{PGC}-1 \beta$ are endogenously regulated by $\mathrm{TH}$ in vivo, (ii) this regulation occurs rapidly via a TRE (at least confirmed for PGC-1 $\alpha$ ), and (iii) a functional interaction with transcription factors which are critical for mitochondrial biogenesis (e.g. TR, ERR and NRF) has been characterised.

\section{Other coactivators and corepressors}


TH alters other coactivators as well (Sadow et al., 2003). The p160 coactivator SRC-1 is positively regulated by $\mathrm{TH}$ and its function is linked to $\mathrm{TH}$ metabolism. SRC-1 plays a role in thermogenesis probably via a coactivation of TR and other nuclear receptors (Picard et al., 2002). Furthermore, SRC-1 knock-out mice display features of thyroid hormone resistance, further emphasising a close connection between SRC-1 and TH (Weiss et al., 1999). However, it has not been evaluated if the TH mediated activation of this cofactor occurs early which is essential for an intermediate factor.

Relatively little is known about the regulation of corepressors. In contrast to the rather ubiquitously expressed corepressors NCoR and SMRT, the corepressor hairless is robustly and rapidly regulated by TH (Ramos and Weiss, 2006). However, since hairless is expressed in a tissue-specific manner (brain and skin) it is unlikely that this corepressor plays a major role in other TH target tissues (Potter et al., 2002).

Another interesting candidate is the corepressor RIP140. RIP140 functions opposes PGC-1 $\alpha$ coactivator and acts as a 'transcriptional brake' on mitochondrial biogenesis (Hock and Kralli, 2009). Whereas PGC-1 $\alpha$ activates mitochondrial biogenesis, RIP140 reduces this activity. RIP140 binds to TR in a ligand-depending manner and may compete for binding with coactivators such as PGC-1 $\alpha$ (Wei and Hu, 2004). RIP140 may also play a role in nucleosome positioning, thereby modifying the access of TR to bind a TRE (Park et al., 2009). However, the induction kinetic of RIP140 has not been tested so far.

\section{A transcriptional network to control TH-mediated regulation of mitochondrial biogenesis}

Taken together, thyroid hormone has at least three different pathways of regulating gene expression of target genes contributing to mitochondrial biogenesis (Figure 3). First, TH binds to nuclear-localised TR and modulates nuclear gene expression via binding to a TRE. Second, TH has a direct effect on the mitochondrion via the binding of a mitochondrial-localised TR. Thirdly, intermediate factors are synthesised (most likely via TREs) which subsequently enter the nucleus and regulate a second series of TH-target genes. As the synthesis of these intermediate proteins takes time, the indirectly regulated genes are expressed with a delay in response to TH in vivo. Consequently physiological alterations like increased oxygen consumption are also delayed (Figure 1). The transcription factors NRF-1, NRF-2 and PPAR $\gamma$ and the coactivators PGC- $1 \alpha$ and PGC-1 $1 \beta$ meet the criteria to serve as intermediate factors. These regulation mechanisms are additionally modulated by many non-genomic actions (e.g. 
post-translational modifications; Figure 2), the local bioavailability or a direct binding of TH (or a derivative thereof) to target structures. The specific composition and modulation of this network in adaptation to nutritive, endocrine and other environmental signals is an interesting research goal for the future.

\section{Figure legends}

\section{Figure 1}

Alteration of oxygen consumption rates after administration of a single dose of thyroid hormone to hypothyroid rats. Thyroid hormone was injected at time 0 and changes in basal metabolic rates were measured at the indicated times. 'eu': metabolic rate of untreated, euthyroid animals; 'hypo': metabolic rate of hypothyroid animals. Modified from Tata et al. (1963).

\section{Figure 2}

Thyroid hormone receptors (TR) are encoded on two different genes and give rise to TR $\alpha$ and TR $\beta$ proteins. The two isoforms contain a common modular domain organisation with an activation domain 1 (AF-1) at the N-terminus, followed by the DNA binding domain (DBD) and the hinge domain. The ligand-binding domain (LBD) and the ligand-depending activation domain 2 (AF-2) are located at the C-terminus. TR $\alpha$ has been described to be posttranslationally modified by acetylation (Ac) within the hinge domain, whereas TR $\beta$ has been described to be phosphorylated (P) within the DBD and ubiquitinated (U) within the LBD.

\section{Figure 3}

Thyroid hormones (THs) are transported via a set of TH transporters into the cell. Intracellular TH is modified by deiodination and possibly decarboxylation. Upon binding of TH to thyroid hormone receptors (TRs), the receptors enter the mitochondrion directly, causing an alteration of mitochondrial gene transcription. Alternatively, TRs enter the nucleus regulating a first set of TH target genes (early expression). Some of these target genes serve as intermediate factors and regulate a second series of TH target genes (late expression). This group of intermediate factors encompasses transcription factors (NRF-1, NRF-2, PPAR $\gamma$ ) and transcriptional coactivators (PGC-1 $\alpha$, PGC-1 $\beta$ ). As a consequence, oxygen consumption rates of mitochondria increase after a lag period of $\sim 48$ hours after the administration of TH in vivo. 


\section{Acknowledgements}

We would like to thank Hans-Joachim Seitz, Johannes Klein, Josef Köhrle and Hendrik Lehnert for their past and current mentorship as well as on-going scientific support.

We apologize to those whose works were not cited through inadvertent omission or because of space limitations.

Reference List

Aquilano,K., Vigilanza,P., Baldelli,S., Pagliei,B., Rotilio,G., and Ciriolo,M.R. (2010).

Peroxisome proliferator-activated receptor gamma co-activator 1alpha (PGC-1alpha) and sirtuin 1 (SIRT1) reside in mitochondria: possible direct function in mitochondrial biogenesis. J. Biol. Chem. 285, 21590-21599.

Attia,R.R., Connnaughton,S., Boone,L.R., Wang,F., Elam,M.B., Ness,G.C., Cook,G.A., and Park,E.A. (2010). Regulation of pyruvate dehydrogenase kinase 4 (PDK4) by thyroid hormone: role of the peroxisome proliferator-activated receptor gamma coactivator (PGC-1 alpha). J. Biol. Chem. 285, 2375-2385.

Bergh,J.J., Lin,H.Y., Lansing,L., Mohamed,S.N., Davis,F.B., Mousa,S., and Davis,P.J. (2005). Integrin alphaVbeta3 contains a cell surface receptor site for thyroid hormone that is linked to activation of mitogen-activated protein kinase and induction of angiogenesis. Endocrinology 146, 2864-2871.

Bungay,A., Selden,C., Brown,D., Malik,R., Hubank,M., and Hodgson,H. (2008). Microarray analysis of mitogenic effects of T3 on the rat liver. J. Gastroenterol. Hepatol. 23, 1926-1933.

Casas,F., Pessemesse,L., Grandemange,S., Seyer,P., Baris,O., Gueguen,N., Ramonatxo,C., Perrin,F., Fouret,G., Lepourry,L., Cabello,G., and Wrutniak-Cabello,C. (2009).

Overexpression of the mitochondrial $\mathrm{T} 3$ receptor induces skeletal muscle atrophy during aging. PLoS. One. 4, e5631.

Casas,F., Rochard,P., Rodier,A., Cassar-Malek,I., Marchal-Victorion,S., Wiesner,R.J., Cabello,G., and Wrutniak,C. (1999). A variant form of the nuclear triiodothyronine receptor c-ErbAalpha1 plays a direct role in regulation of mitochondrial RNA synthesis. Mol. Cell Biol. 19, 7913-7924.

Chattopadhyay,S., Sahoo,D.K., Subudhi,U., and Chainy,G.B. (2007). Differential expression profiles of antioxidant enzymes and glutathione redox status in hyperthyroid rats: a temporal analysis. Comp Biochem. Physiol C. Toxicol. Pharmacol. 146, 383-391. 
Chen,R.N., Huang,Y.H., Lin,Y.C., Yeh,C.T., Liang,Y., Chen,S.L., and Lin,K.H. (2008). Thyroid hormone promotes cell invasion through activation of furin expression in human hepatoma cell lines. Endocrinology 149, 3817-3831.

Chen,S.L., Chang,Y.J., Wu,Y.H., and Lin,K.H. (2003). Mitogen-activated protein kinases potentiate thyroid hormone receptor transcriptional activity by stabilizing its protein. Endocrinology 144, 1407-1419.

Cheng,S.Y., Leonard,J.L., and Davis,P.J. (2010). Molecular aspects of thyroid hormone actions. Endocr. Rev. 31, 139-170.

Clement,K., Viguerie,N., Diehn,M., Alizadeh,A., Barbe,P., Thalamas,C., Storey,J.D., Brown,P.O., Barsh,G.S., and Langin,D. (2002). In vivo regulation of human skeletal muscle gene expression by thyroid hormone. Genome Res. 12, 281-291.

Cooper,D.S. (2003). Hyperthyroidism. Lancet 362, 459-468.

Dace,A., Zhao,L., Park,K.S., Furuno,T., Takamura,N., Nakanishi,M., West,B.L., Hanover,J.A., and Cheng,S. (2000). Hormone binding induces rapid proteasome-mediated degradation of thyroid hormone receptors. Proc. Natl. Acad. Sci. U. S. A 97, 8985-8990.

Denver,R.J., Pavgi,S., and Shi,Y.B. (1997). Thyroid hormone-dependent gene expression program for Xenopus neural development. J. Biol. Chem. 272, 8179-8188.

Denver,R.J. and Williamson,K.E. (2009). Identification of a thyroid hormone response element in the mouse Kruppel-like factor 9 gene to explain its postnatal expression in the brain. Endocrinology 150, 3935-3943.

DiMauro,S. and Schon,E.A. (2003). Mitochondrial respiratory-chain diseases. N. Engl. J. Med. 348, 2656-2668.

Dong,H., Yauk,C.L., Rowan-Carroll,A., You,S.H., Zoeller,R.T., Lambert,I., and Wade,M.G. (2009). Identification of thyroid hormone receptor binding sites and target genes using ChIPon-chip in developing mouse cerebellum. PLoS. One. 4, e4610.

Feng,X., Jiang,Y., Meltzer,P., and Yen,P.M. (2000). Thyroid hormone regulation of hepatic genes in vivo detected by complementary DNA microarray. Mol. Endocrinol. 14, 947-955.

Flores-Morales,A., Gullberg,H., Fernandez,L., Stahlberg,N., Lee,N.H., Vennstrom,B., and Norstedt,G. (2002). Patterns of liver gene expression governed by TRbeta. Mol. Endocrinol. $16,1257-1268$.

Franko,A., Mayer,S., Thiel,G., Mercy,L., Arnould,T., Hornig-Do,H.T., Wiesner,R.J., and Goffart,S. (2008). CREB-1alpha is recruited to and mediates upregulation of the cytochrome c promoter during enhanced mitochondrial biogenesis accompanying skeletal muscle differentiation. Mol. Cell Biol. 28, 2446-2459.

Friesema,E.C., Visser,W.E., and Visser,T.J. (2010). Genetics and phenomics of thyroid hormone transport by MCT8. Mol. Cell Endocrinol. 322, 107-113.

Gugneja,S., Virbasius,J.V., and Scarpulla,R.C. (1995). Four structurally distinct, non-DNAbinding subunits of human nuclear respiratory factor 2 share a conserved transcriptional activation domain. Mol. Cell Biol. 15, 102-111. 
Harper,M.E. and Seifert,E.L. (2008). Thyroid hormone effects on mitochondrial energetics. Thyroid 18, 145-156.

Helbing,C.C., Werry,K., Crump,D., Domanski,D., Veldhoen,N., and Bailey,C.M. (2003). Expression profiles of novel thyroid hormone-responsive genes and proteins in the tail of Xenopus laevis tadpoles undergoing precocious metamorphosis. Mol Endocrinol 17, 1395409.

Hock,M.B. and Kralli,A. (2009). Transcriptional control of mitochondrial biogenesis and function. Annu. Rev. Physiol 71, 177-203.

Huo,L. and Scarpulla,R.C. (2001). Mitochondrial DNA instability and peri-implantation lethality associated with targeted disruption of nuclear respiratory factor 1 in mice. Mol. Cell Biol. 21, 644-654.

Irrcher,I., Adhihetty,P.J., Sheehan,T., Joseph,A.M., and Hood,D.A. (2003). PPARgamma coactivator-1alpha expression during thyroid hormone- and contractile activity-induced mitochondrial adaptations. Am J Physiol Cell Physiol 284, C1669-C1677.

Leigh-Brown,S., Enriquez,J.A., and Odom,D.T. (2010). Nuclear transcription factors in mammalian mitochondria. Genome Biol. 11, 215.

Lin,H.Y., Zhang,S., West,B.L., Tang,H.Y., Passaretti,T., Davis,F.B., and Davis,P.J. (2003). Identification of the putative MAP kinase docking site in the thyroid hormone receptor-betal DNA-binding domain: functional consequences of mutations at the docking site.

Biochemistry 42, 7571-7579.

Miller,L.D., Park,K.S., Guo,Q.M., Alkharouf,N.W., Malek,R.L., Lee,N.H., Liu,E.T., and Cheng,S.Y. (2001). Silencing of Wnt signaling and activation of multiple metabolic pathways in response to thyroid hormone-stimulated cell proliferation. Mol Cell Biol 21, 6626-39.

Mochizuki,K., Sakaguchi,N., Takabe,S., and Goda,T. (2007). De-phosphorylation of TRalpha-1 by p44/42 MAPK inhibition enhances T(3)-mediated GLUT5 gene expression in the intestinal cell line Caco-2 cells. Biochem. Biophys. Res. Commun. 359, 979-984.

Moreno,M., de,L.P., Lombardi,A., Silvestri,E., Lanni,A., and Goglia,F. (2008). Metabolic effects of thyroid hormone derivatives. Thyroid 18, 239-253.

Ongwijitwat,S., Liang,H.L., Graboyes,E.M., and Wong-Riley,M.T. (2006). Nuclear respiratory factor 2 senses changing cellular energy demands and its silencing down-regulates cytochrome oxidase and other target gene mRNAs. Gene 374, 39-49.

Park,S.W., Huang,W.H., Persaud,S.D., and Wei,L.N. (2009). RIP140 in thyroid hormonerepression and chromatin remodeling of Crabpl gene during adipocyte differentiation. Nucleic Acids Res. 37, 7085-7094.

Phan,T.Q., Jow,M.M., and Privalsky,M.L. (2010). DNA recognition by thyroid hormone and retinoic acid receptors: 3,4,5 rule modified. Mol. Cell Endocrinol. 319, 88-98.

Picard,F., Gehin,M., Annicotte,J., Rocchi,S., Champy,M.F., O'Malley,B.W., Chambon,P., and Auwerx,J. (2002). SRC-1 and TIF2 control energy balance between white and brown adipose tissues. Cell 111, 931-941. 
Piehl,S., Hoefig,C.S., Scanlan,T.S., and Kohrle,J. (2011). Thyronamines--past, present, and future. Endocr. Rev. 32, 64-80.

Potter,G.B., Zarach,J.M., Sisk,J.M., and Thompson,C.C. (2002). The thyroid hormoneregulated corepressor hairless associates with histone deacetylases in neonatal rat brain. Mol. Endocrinol. 16, 2547-2560.

Psarra,A.M. and Sekeris,C.E. (2009). Glucocorticoid receptors and other nuclear transcription factors in mitochondria and possible functions. Biochim. Biophys. Acta 1787, 431-436.

Puigserver,P., Wu,Z., Park,C.W., Graves,R., Wright,M., and Spiegelman,B.M. (1998). A cold-inducible coactivator of nuclear receptors linked to adaptive thermogenesis. Cell 92, 829-39.

Quignodon,L., Grijota-Martinez,C., Compe,E., Guyot,R., Allioli,N., Laperriere,D., Walker,R., Meltzer,P., Mader,S., Samarut,J., and Flamant,F. (2007). A combined approach identifies a limited number of new thyroid hormone target genes in post-natal mouse cerebellum. J. Mol. Endocrinol. 39, 17-28.

Ramos,H.E. and Weiss,R.E. (2006). Regulation of nuclear coactivator and corepressor expression in mouse cerebellum by thyroid hormone. Thyroid 16, 211-216.

Rebelo,A.P., Williams,S.L., and Moraes,C.T. (2009). In vivo methylation of mtDNA reveals the dynamics of protein-mtDNA interactions. Nucleic Acids Res. 37, 6701-6715.

Ristevski,S., O'Leary,D.A., Thornell,A.P., Owen,M.J., Kola,I., and Hertzog,P.J. (2004). The ETS transcription factor GABPalpha is essential for early embryogenesis. Mol. Cell Biol. 24, 5844-5849.

Roberts,C.G. and Ladenson,P.W. (2004). Hypothyroidism. Lancet 363, 793-803.

Rodriguez-Pena,A., Escriva,H., Handler,A.C., and Vallejo,C.G. (2002). Thyroid hormone increases transcription of GA-binding protein/nuclear respiratory factor-2 alpha-subunit in rat liver. FEBS Lett. 514, 309-314.

Sadana,P., Zhang,Y., Song,S., Cook,G.A., Elam,M.B., and Park,E.A. (2007). Regulation of carnitine palmitoyltransferase I (CPT-Ialpha) gene expression by the peroxisome proliferator activated receptor gamma coactivator (PGC-1) isoforms. Mol. Cell Endocrinol. 267, 6-16.

Sadow,P.M., Chassande,O., Koo,E.K., Gauthier,K., Samarut,J., Xu,J., O'Malley,B.W., and Weiss,R.E. (2003). Regulation of expression of thyroid hormone receptor isoforms and coactivators in liver and heart by thyroid hormone. Mol. Cell Endocrinol. 203, 65-75.

Sanchez-Pacheco,A., Martinez-Iglesias,O., Mendez-Pertuz,M., and Aranda,A. (2009). Residues K128, 132, and 134 in the thyroid hormone receptor-alpha are essential for receptor acetylation and activity. Endocrinology 150, 5143-5152.

Santos,G.M., Fairall,L., and Schwabe,J.W. (2011). Negative regulation by nuclear receptors: a plethora of mechanisms. Trends Endocrinol. Metab 22, 87-93.

Scarpulla,R.C. (2008). Transcriptional paradigms in mammalian mitochondrial biogenesis and function. Physiol Rev. 88, 611-638. 
Schmidt,O., Pfanner,N., and Meisinger,C. (2010). Mitochondrial protein import: from proteomics to functional mechanisms. Nat. Rev. Mol. Cell Biol. 11, 655-667.

Shih,C.H., Chen,S.L., Yen,C.C., Huang,Y.H., Chen,C.D., Lee,Y.S., and Lin,K.H. (2004). Thyroid hormone receptor-dependent transcriptional regulation of fibrinogen and coagulation proteins. Endocrinology 145, 2804-14.

Silvestri,E., Moreno,M., Schiavo,L., de,L.P., Lombardi,A., Chambery,A., Parente,A., Lanni,A., and Goglia,F. (2006). A proteomics approach to identify protein expression changes in rat liver following administration of 3,5,3'-triiodo-L-thyronine. J. Proteome. Res. 5, 23172327.

Stahlberg,N., Merino,R., Hernandez,L.H., Fernandez-Perez,L., Sandelin,A., Engstrom,P., Tollet-Egnell,P., Lenhard,B., and Flores-Morales,A. (2005). Exploring hepatic hormone actions using a compilation of gene expression profiles. BMC. Physiol 5, 8.

TATA,J.R., ERNSTER,L., LINDBERG,O., ARRHENIUS,E., PEDERSEN,S., and HEDMAN,R. (1963). The action of thyroid hormones at the cell level. Biochem. J. 86, 408428.

Venditti,P., Bari,A., Di,S.L., Cardone,A., Della,R.F., D'Esposito,M., and Di,M.S. (2009). Involvement of PGC-1, NRF-1, and NRF-2 in metabolic response by rat liver to hormonal and environmental signals. Mol. Cell Endocrinol. 305, 22-29.

Ventura-Clapier,R., Garnier,A., and Veksler,V. (2008). Transcriptional control of mitochondrial biogenesis: the central role of PGC-1alpha. Cardiovasc. Res. 79, 208-217.

Wei,L.N. and Hu,X. (2004). Receptor interacting protein 140 as a thyroid hormonedependent, negative co-regulator for the induction of cellular retinoic acid binding protein I gene. Mol. Cell Endocrinol. 218, 39-48.

Weiss,R.E., Xu,J., Ning,G., Pohlenz,J., O'Malley,B.W., and Refetoff,S. (1999). Mice deficient in the steroid receptor co-activator 1 (SRC-1) are resistant to thyroid hormone. EMBO J. 18, 1900-1904.

Weitzel,J.M. (2008). To bind or not to bind - how to down-regulate target genes by liganded thyroid hormone receptor? Thyroid Res. 1, 4.

Weitzel,J.M., Grott,S., Radtke,C., Kutz,S., and Seitz,H.J. (2000). Multiple promoters direct the tissue-specific expression of rat mitochondrial glycerol-3-phosphate dehydrogenase. Biol. Chem. 381, 611-614.

Weitzel,J.M., Hamann,S., Jauk,M., Lacey,M., Filbry,A., Radtke,C., Iwen,K.A., Kutz,S., Harneit,A., Lizardi,P.M., and Seitz,H.J. (2003). Hepatic gene expression patterns in thyroid hormone-treated hypothyroid rats. J Mol Endocrinol 31, 291-303.

Weitzel,J.M., Radtke,C., and Seitz,H.J. (2001). Two thyroid hormone-mediated gene expression patterns in vivo identified by cDNA expression arrays in rat. Nucleic Acids Res 29, 5148-55.

Wulf,A., Harneit,A., Kroger,M., Kebenko,M., Wetzel,M.G., and Weitzel,J.M. (2008). T3mediated expression of PGC-1alpha via a far upstream located thyroid hormone response element. Mol. Cell Endocrinol. 287, 90-95. 
Wulf,A., Harneit,A., and Weitzel,J.M. (2007). T3-mediated gene expression is independent of PGC-1alpha. Mol. Cell Endocrinol. 270, 57-63. 
Figure 1

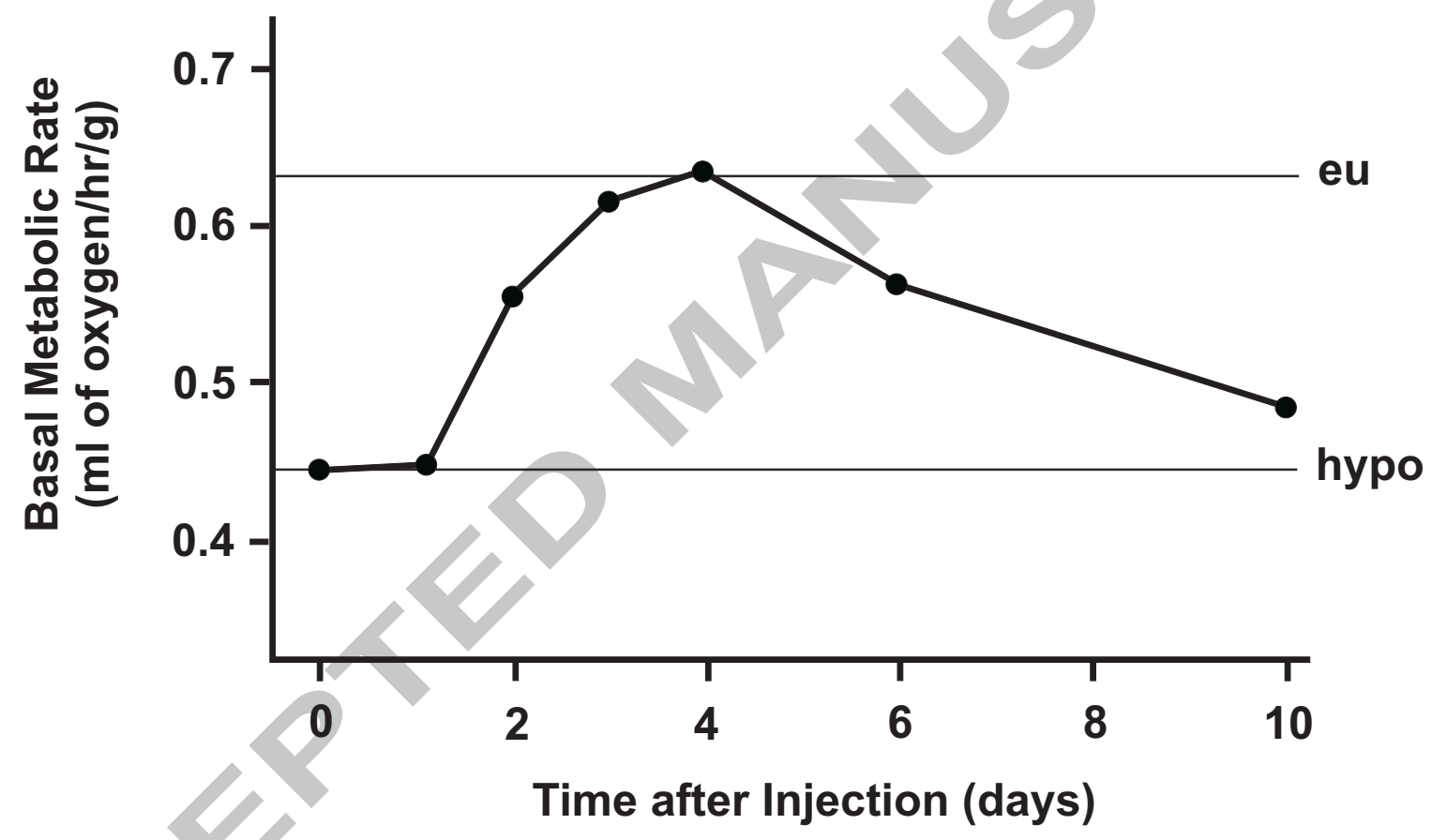


Figure 2

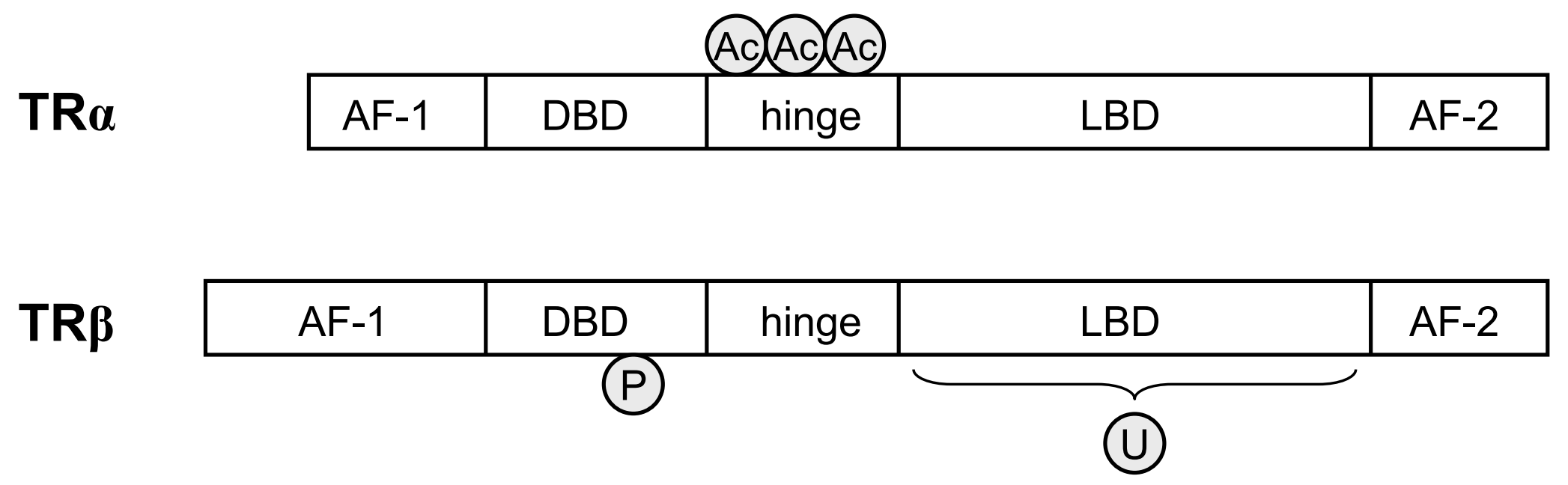




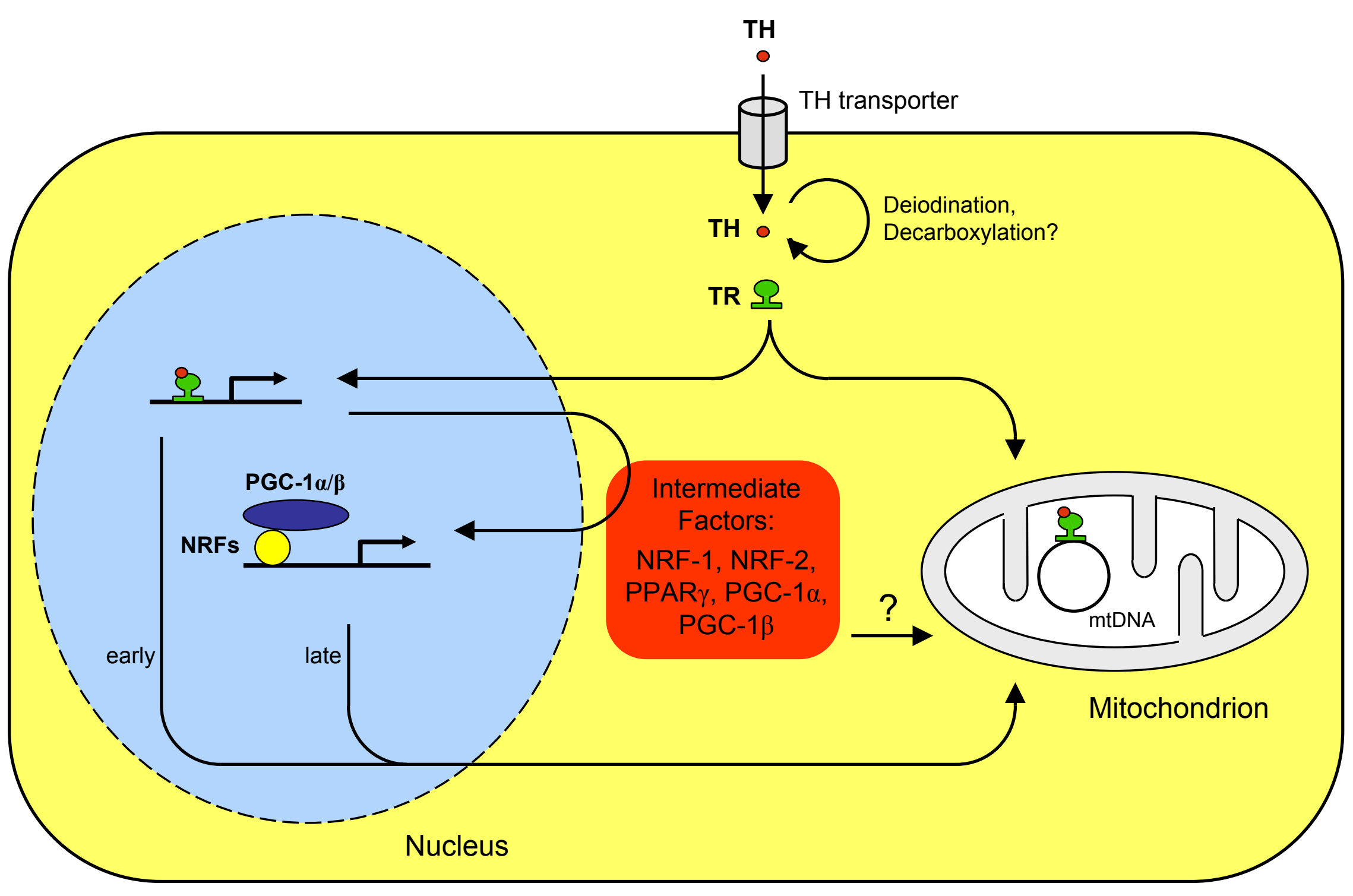

Fiqure 3 
$>$ We developed a model for different time courses in thyroid hormone-mediated gene transcription. $>$ Early induced thyroid hormone target genes are direct targets via thyroid hormone receptors. $>$ Late induced thyroid hormone target genes are regulated via intermediate factors. > Intermediate factors of thyroid hormone action are defined. 